\title{
Dominance in monkeys: Sex differences
}

W. F. ANGERMEIER, J. B. PHELPS, S. MURRAY, and J. HOWANSTINE, Florida Presbyterian College, St. Petersburg, Florida 33733

Eight female rhesus monkeys were paired under laboratory conditions for the purpose of dominance determinations. Data from a previous identical study with males were compared with the data obtained here. Males showed a significantly higher incidence of vocalization, fighting and avoidance. Dominance in males seems to depend primarily on the aggressive initiative of the dominant animal. In females, dominance appears to be determined primarily by the initiative of the subdominant animal in avoiding the dominant one.

Social dominance relationships exist in all primates. The hierarchical system which characterizes dominance seems to be expressed most clearly in rhesus monkeys and in baboons, where the defense of the group consists of a combination of aggression and cooperation, since escape into trees is absent (Price, 1967). Behavior associated with dominance in feral primates has been thoroughly studied by many investigators (Carpenter, 1963; Altmann, 1962; Manocha, 1966, among others). Studies on dominance in captive primates are fewer (Ploog, 1966; Angermeier, Phelps, Murray, \& Reynolds, 1967; Angermeier, Phelps, Oreste, Davis, \& Reynolds, 1967; Angermeier, Phelps, Reynolds, \& Davis, 1968, among others).

The study presented here is an extension of previously reported work on social dominance in captive rhesus monkeys and is concerned primarily with the assessment of male-female differences in the establishment of dominance.

\section{METHOD}

Subjects

Eight female rhesus monkeys, ranging in weights from 4021 to $5606 \mathrm{~g}$, were used as Ss. Animals were originally obtained from a dealer in India and had been housed in single cages in our laboratory for a period of six months. All animals were experimentally naive and were maintained on a regular diet of daily fresh fruit, laboratory chow and ad lib water.

Apparatus

The dimensions of the clear plastic cage set in a metal frame in which the animals were paired for dominance determinations were $88 \times 124 \times 186 \mathrm{~cm}$. This cage was placed in an otherwise empty testing room, where Ss could be observed from an adjacent room through a large one-way window.

Procedure

All animals were weighed and divided into two weight-groups: Group 1 contained four Ss weighing between 4021 and $4870 \mathrm{~g}$; Group 2 was comprised of four Ss weighing between 5153 and $5606 \mathrm{~g}$. All animals were paired with all other animals in this order: During the first three days animals from Groups 1 and 2 were paired only with animals coming from their respective weight group; during the last four days, animals from Group 1 were paired only with animals from Group 2 . The rationale for this part of the procedure stemmed from a previous observation of the importance of weight differences in dominance determinations which we sought to minimize in this study (Angermeier \& Phelps, 1967). Each animal was paired with one other animal only once per day. Thus, a total of 28 pairings occurred. Animals remained in the testing cage between 15 and $30 \mathrm{~min}$, the time interval it took to reach unanimous agreement among four trained observers regarding the results of the test.

\section{RESULTS}

Weight differences had little or no effect upon the outcome of the dominance tests conducted here. As observed in an earlier study with male monkeys, however, here, too, no female animal was found to be dominant over another animal when the weight difference was $1000 \mathrm{~g}$ or more in favor of the other animal. A summary of the observed behavior and the significant differences between observations of this study and one reported earlier
Table 1

Differences in Dominance Behavior Between Male and Female Rhesus. Monkeys

\begin{tabular}{|c|c|c|c|c|c|c|}
\hline \multirow{2}{*}{ Behavior } & \multicolumn{6}{|c|}{ Number of Tests in Which Behavior Occurred* } \\
\hline & No. & Per cent & No. & Per cent & $t$ & $\mathrm{p}$ \\
\hline Stalking & 14 & 52 & 15 & 56 & 0.40 & NS \\
\hline Mounting & 16 & 59 & 9 & 33 & 1.89 & NS \\
\hline Grooming & 5 & 19 & 9 & 33 & 1.17 & NS \\
\hline Biting & 7 & 26 & 7 & 26 & 0.00 & NS \\
\hline Vocalization & 9 & 33 & 1 & 4 & 2.06 & $<.05$ \\
\hline Fighting & 27 & 100 & 4 & 15 & 4.21 & $<.01$ \\
\hline Genital Inspection & 12 & 44 & 5 & 19 & 1.84 & NS \\
\hline Sexual Presentation & 9 & 33 & 4 & 15 & 1.43 & NS \\
\hline Baring of Teeth & 12 & 44 & 5 & 19 & 1.84 & NS \\
\hline Avoidance & 25 & 93 & 17 & 63 & 2.11 & $<.05$ \\
\hline
\end{tabular}

* Number of pairings presented here reduced to 27: no interaction in one test.

(Angermeier, Phelps, Murray, \& Reynolds, 1967) is shown in Table 1.

\section{DISCUSSION}

The most striking contrast in the establishment of dominance between male and female paired rhesus monkeys occurs in the category of fighting. All 27 pairings of male partners produced fights, whereas only four of 27 female pairings resulted in fights. Furthermore, it was observed that in dominance tests involving males, fighting and other forms of aggression were always the first event to take place after the animals were put into the testing cage. This was not true in the dominance tests involving females. The most prominent behavior observed in these situations was avoidance on the part of the subdominant animal. Another observation should be mentioned here. When an extraneous stimulus or threat was introduced into the testing situation (such as handlers entering the room at the end of testing), the subdominant female always moved into close proximity to the dominant animal. This behavior was only rarely seen in males. Generally speaking, it may be said that females are much less aggressive than males when dominance is to be established. The manner in which the two systems of behavior will be integrated when males and females are paired under the conditions described is presently under investigation.

\section{REFERENCES}

ALTMANN, S. A. A field study of the sociology of rhesus monkeys, Macaca mulatta. Annals of the New York Academy of Science, 1962, 102, 338435 .

ANGERMEIER, W. F., \& PHELPS, J. B. Dominance in monkeys: Behavior and biochemistry. 6571st Aeromedical Research Laboratory Technical Report No. 6571st ARL-TR-67-24.

ANGERMEIER, W. F., PHELPS, J. B., MURRAY, S., \& REYNOLDS, H. H. Dominance in monkeys: Early rearing and home environment. Psychonomic Science, 1967, 9, 433-434.

ANGERMEIER, W. F., PHELPS, J. B., ORESTE, M., DAVIS, H., \& REYNOLDS, H. H. Dominance hierarchies in monkeys. Psychonomic Science, $1967,9,435-436$.

ANGERMEIER, W. F., PHELPS, J. B., REYNOLDS, H. H., \& DAVIS, R. Dominance in monkeys: Effects of social change on performance and biochemistry.Psychonomic Science, 1968, 11, 183-184.

CARPENTER, C. R. Societies of monkeys and apes. In C. H. Southwick (Ed.), Primate social behavior. New York: D. Van Nostrand Company, Inc., 1963. Pp. 24-51.

MANOCHA, S. N. A comparative study of rhesus monkeys and langurs: Free social behavior. Psychological Studies, 1966, 11, 23-30.

PLOOG, D. Experimentelle Verhaltensforschung. Der Nervenarzt, 1966, 37 , 443-447.

PRICE, J. The dominance hierarchy and the evolution of mental illness. The Lancet, 1967, 243-246. 